\title{
Accurate detection of lameness in dairy cattle with computer vision: A new and individualized detection strategy based on the analysis of the supporting phase
}

\author{
X. Kang, ${ }^{1,2} \odot$ X. D. Zhang, ${ }^{1,2} \odot$ and G. Liu ${ }^{1,2 *} \odot$ \\ ${ }^{1}$ Key Lab of Modern Precision Agriculture System Integration Research, Ministry of Education of China, China Agricultural University, Beijing, \\ P.R. China 100083 \\ ${ }^{2}$ Key Lab of Agricultural Information Acquisition Technology, Ministry of Agricultural of China, China Agricultural University, Beijing, \\ P.R. China 100083
}

\section{ABSTRACT}

Lameness has a considerable influence on the welfare and health of dairy cows. Many attempts have been made to develop automatic lameness detection systems using computer vision technology. However, these detection methods are easily affected by the characteristics of individual cows, resulting in inaccurate detection of lameness. Therefore, this study explores an individualized lameness detection method for dairy cattle based on the supporting phase using computer vision. This approach is applied to eliminate the influence of the characteristics of individual cows and to detect lame cows and lame hooves. In this paper, the correlation coefficient between lameness and the supporting phase is calculated, a lameness detection algorithm based on the supporting phase is proposed, and the accuracy of the algorithm is verified. Additionally, the reliability of this method using computer vision technology is verified based on deep learning. One hundred naturally walking cows are selected from video data for analysis. The results show that the correlation between lameness and the supporting phase was $0.864 ; 96 \%$ of cows were correctly classified, and $93 \%$ of lame hooves were correctly detected using the supporting phase-based lameness detection algorithm. The mean average precision is $87.0 \%$, and the number of frames per second is 83.3 when the Receptive Field Block Net Single Shot Detector deep learning network was used to detect the locations of cow hooves in the video. The results show that the supporting phase-based lameness detection method proposed in this paper can be used for the detection and classification of cow lameness and the detection of

Received January 30, 2020.

Accepted May 19, 2020.

*Corresponding author: pac@cau.edu.cn lame hooves with high accuracy. This approach eliminates the influence of individual cow characteristics and could be integrated into an automatic detection system and widely applied for the detection of cow lameness. Key words: computer vision technology, dairy cattle, lameness detection, supporting phase, deep learning

\section{INTRODUCTION}

Lameness not only affects milk production (de Mol et al., 2013; Liang et al., 2017; Sjöström et al., 2018) but also reduces the reproductive capacity and welfare of cows (Green et al., 2002; Booth et al., 2004; Rees, 2014; Adams et al., 2017; Grimm et al., 2019). Therefore, it is very important to achieve the early detection of lameness in dairy cows and implement effective treatment measures, mainly trimming and medication. The methods of detecting lameness in dairy cattle have been widely studied, such as assessments of speed reduction, stride changes, back arch, and head bob (Flower and Weary, 2009; Liu et al., 2011; Pluk et al., 2012; Hoffman et al., 2014; Jones, 2017; Zillner et al., 2018). These behavioral changes are interpreted as compensation for pain relief and provide an important basis for lameness detection (Scott, 1989; Adair et al., 2019). To quantify the degree of lameness in dairy cattle, locomotion scoring systems are widely used, which are typically based on a 5 -point system. In accordance with the movement of dairy cattle, the degree of lameness can be classified in a range from 1 point (no lameness) to 5 points (severe lameness; Sprecher et al., 1997; Winckler and Willen, 2001; Flower et al., 2006). Due to the timeconsuming and laborious nature of manual observations and the subjective influence of the observer (Leach et al., 2013), research on the detection of cow lameness has begun to develop toward automation (Van Nuffel et al., 2013, 2015), including the application of pressure sensors (Pastell et al., 2008a,b, 2010; Poikalainen et al., 
2010; Maertens et al., 2011), accelerometers (Walker et al., 2008; Van Hertem et al., 2013; Alsaaod et al., 2014; Thorup et al., 2015; Mandel et al., 2018), and computer vision technology (Song et al., 2008; Viazzi et al., 2013, 2014; Zhao et al., 2018). The locomotion scores and foot pathologies are usually used as the reference standards for the validation of automatic lameness detection systems (Alsaaod et al., 2019). The assessment methods used in automatic lameness detection using imageprocessing techniques are mostly based on the locomotion characteristics of cows. However, this approach is affected by the characteristics of individual cows (Pluk et al., 2010; Viazzi et al., 2013), and investigations have shown that farms are particularly concerned with identifying which specific hoof is lame (Van Hertem et al., 2016). Therefore, it is necessary to develop a method of detecting lameness that can eliminate the influence of individual cow characteristics and identify which hoof is experiencing lameness.

Based on long-term observations and analyses of cow walking, we have found that there is a strong correlation between the supporting phase of a cow's hoof and the lameness of the cow. When a lame cow walks, the supporting phase of the affected hoof will be significantly altered because of the reduction in the stress that the hoof can bear due to pain (Rajkondawar et al., 2006). Because lameness in dairy cattle is mainly caused by hoof disease (Murray et al., 1996), the hoof characteristics can directly reflect the lameness of dairy cattle (Pastell and Kujala, 2007), and because the supporting phase represents a single hoof rather than the whole body of the cow, analyses based on the supporting phase can eliminate the influence of individual differences among dairy cattle to some degree and allow the specific hoof that is causing lameness to be clearly identified.

In recent years, studies of cow lameness detection based on traditional image processing, which is one type of computer vision (Song et al., 2007, 2018), have mostly involved image extraction focusing on the key parts of cows (Pluk et al., 2010; Kang et al., 2019); however, this process is easily disrupted by external factors, such as environmental noise (Poursaberi et al., 2010). With the development of deep learning technology, however, image detection methods that can effectively and accurately extract targets and features from complex backgrounds are becoming increasingly popular. Furthermore, deep learning technology meets the requirements for the high-precision detection of the key parts of cows in natural scenes (Jiang et al., 2019), and such methods can be used for the automatic detection of lameness in dairy cows.
Therefore, in this paper, a lameness detection strategy based on an analysis of the supporting phase is proposed for the identification of lame hooves. Additionally, the correlation between lameness and the supporting phase is further investigated to verify the feasibility of the proposed detection strategy. Finally, computer vision and deep learning techniques are used to capture the hooves of cows, with the aim of verifying that the supporting phase of a cow's hoof can be effectively investigated by means of computer vision technology to facilitate research on lameness detection in the supporting phase, and the results verify the feasibility of the proposed method for automatic lameness detection.

\section{MATERIALS AND METHODS}

\section{Image Acquisition}

The study was carried out at the Dadiqunsheng farm in Beijing, China, in December 2018. The herd consisted of 600 lactating Holstein cows. One hundred multiparous lactating Holstein cows were randomly selected (Main et al., 2010), and their lameness was manually scored by 2 trained observers through both on-farm examinations after milking and video-based assessment. The experimental setup was a passing alley (4 $\mathrm{m}$ long and $1.2 \mathrm{~m}$ wide) located at the entrance of the milking parlor. Cows enter the milking parlor through the passing alley. The data were collected before milking because cows bear more weight at this time than they do after milking; thus, the influence of lameness on the supporting phase during walking is more obvious at this time (Flower et al., 2006). A digital camera (DC-GH5S, Panasonic, Osaka, Japan) was fixed on a tripod $6 \mathrm{~m}$ from the side of the passing alley (Figure 1).

The video was recorded as the cows were passing individually and freely through the alley. The video resolution was $1,920 \times 1,080$ pixels, and the frame rate of the camera was 50 frames/s. The entire body of each cow and the cows' movements were recorded on video (Figure 2).

\section{Locomotion Scoring by Visual Observation}

The locomotion of the cows was scored by 2 trained observers. The scoring method used a simplified standard scale with values of 1 (no lameness), 2 (mild lameness), and 3 (severe lameness) to increase the reliability of the expert scores (Engel et al., 2003; O'Callaghan et al., 2003). Each observer scored the cows in on-farm examinations after milking and twice on video. The 


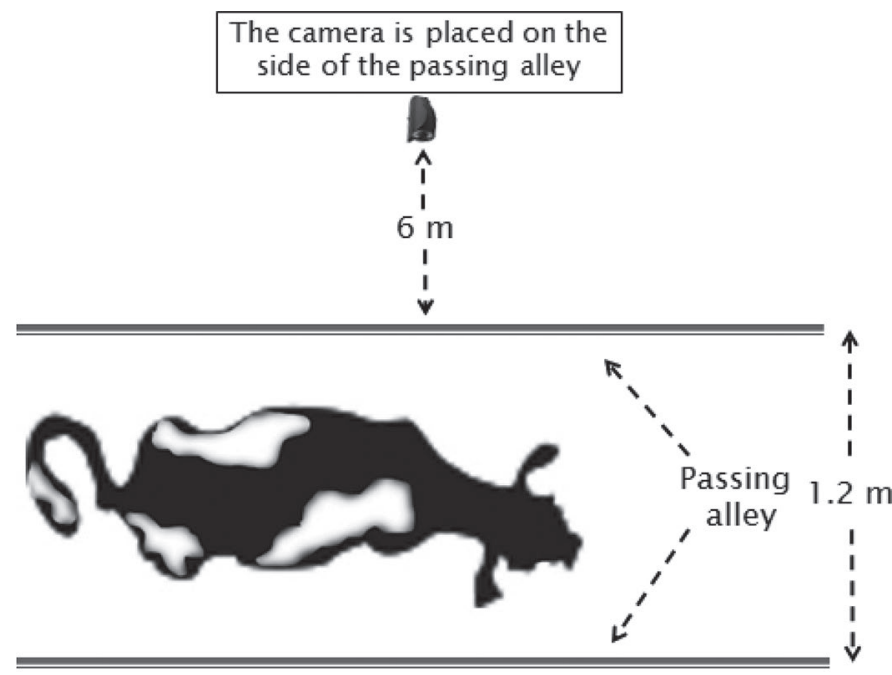

Figure 1. Top view of the video data collection system for walking cows.

average value of the locomotion scores for each cow was used as a reference.

\section{Supporting Phase Calculations}

The video was divided into JPG-format images, and supporting phase information was obtained based on the hoof positions. The hoof positions were manually marked in the images. The load time and lifting time of each of the 4 hooves of each cow were identified during walking. The supporting phase was defined as the time when the hoof of the cow was touching the ground and did not move (Figure 3). The supporting phase of a cow's hoof is represented by Equation 1:

$$
\text { supporting phase }=T_{\text {Lift }}-T_{\text {Land }},
$$

where $T_{\text {Lift }}$ is the hoof lifting time and $T_{\text {Land }}$ is the hoof load time.

\section{Classification Algorithm}

This paper proposes a lameness classification algorithm based on the analysis of data for the supporting phase. The detection threshold varies with the movement speed of the cow. Therefore, the cows were divided into 3 classes by their speed levels (high, medium, and low):

$$
\operatorname{Cow}_{L}=\left(\operatorname{Cow}_{i} \mid t_{\operatorname{maxi}} \leq t_{L s}\right)
$$

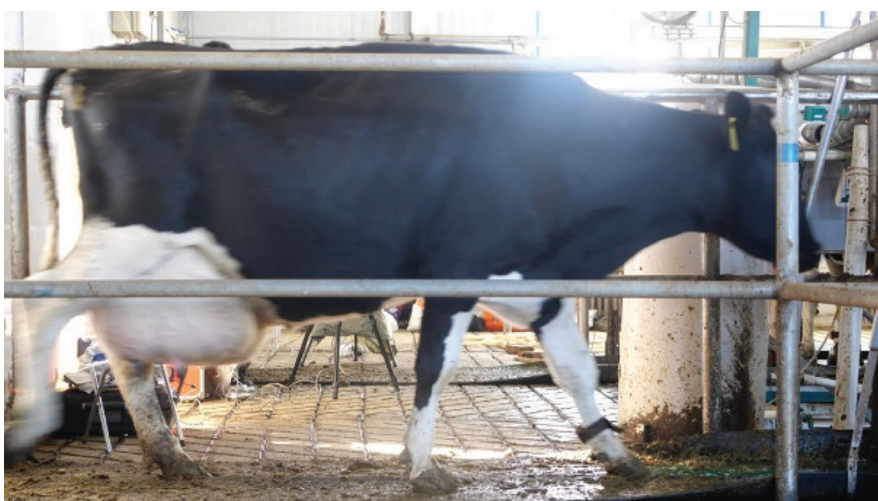

Figure 2. Example image from a video recording. A cow enters the milking parlor.

$$
\begin{gathered}
\operatorname{Cow}_{M}=\left(\operatorname{Cow}_{i} \mid t_{L s} \leq t_{\text {maxi }} \leq t_{H s}\right), \\
\text { Cow }_{H}=\left(\text { Cow }_{i} \mid t_{H s} \leq t_{\text {maxi }}\right),
\end{gathered}
$$

where Cow $_{i}$ denotes the supporting phase of the ith cow; Cow, Cow $_{M}$, and Cow $_{H}$ denote the low, medium, and high speed classes, respectively; $t_{\operatorname{maxi}}$ denotes the maximum supporting phase of the $i$ th cow; and $t_{L s}$ and $t_{H s}$ are the thresholds for speed classification.

The difference between the maximum and minimum values among the 4 supporting phases for each cow is used to characterize the degree of lameness. For cows in different speed classes, different thresholds are set for lameness classification. In this case, we use the high speed class as an example:

$$
\operatorname{Cow}_{i}=\left\{\begin{array}{cc}
1, & t_{\text {maxi }}-t_{\text {mini }}<t_{H 1} \\
2, & t_{H 1} \leq t_{\text {maxi }}-t_{\text {mini }}<t_{H 2} \\
3, & t_{H 2} \leq t_{\operatorname{maxi}}-t_{\min i}
\end{array}\right\},
$$
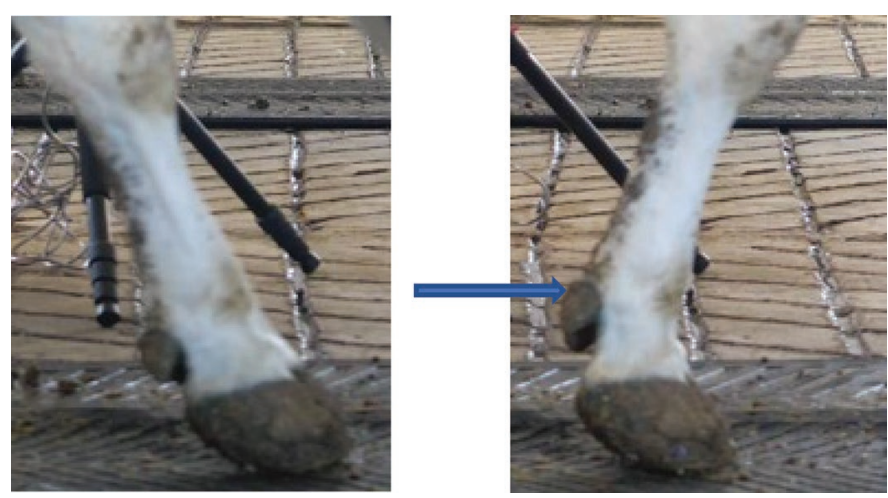

Figure 3. Example of the supporting phase. A hoof touches the ground and is later lifted from the ground. The supporting phase is the time during which the cow's hoof is not moving. 
where $t_{H 1}$ and $t_{H 2}$ are the thresholds for locomotion score classification for cows in the high speed class, $t_{\text {maxi }}$ is the maximum supporting phase of the $i$ th cow, and $t_{\min i}$ is the minimum supporting phase of the $i$ th cow.

\section{Image Processing}

Due to the complex background of a farm (Song et al., 2008), the results can easily be affected by the environmental background when cow features are acquired using conventional image processing technology (Jiang et al., 2019). In this study, the Receptive Field Block Net Single Shot Detector (RFB_Net_SSD) deep learning network (Liu et al., 2018), with high real-time speed and accuracy, was selected for the tracking and positioning of cow legs. One thousand cow images from the video were randomly selected as the original training images, and 500 were selected as the test images.

\section{RESULTS}

\section{Correlation}

The supporting phases of the 4 hooves of each cow were recorded, as shown in Figure 4. The results show a strong correlation between the supporting phase and the degree of lameness. The Spearman rank correlation coefficient was calculated for the locomotion score and the difference in the supporting phases for 100 cows, and the correlation coefficient was found to be 0.864 (Song et al., 2007). A normally walking cow has only a small difference between the maximum and minimum supporting phases, whereas the difference in the hoof supporting phases for a cow with severe lameness is significant.

The results show that lameness will indeed affect the supporting phases of cows. The 4 supporting phases of each cow are connected by lines in the plots in Figure 4 , where the lengths of the connecting lines represent the differences in the supporting phases. The average lengths of the lines in Figure $4 \mathrm{a}, \mathrm{b}$, and $\mathrm{c}$ are 0.057, 0.183 , and $0.394 \mathrm{~s}$, respectively. For a lame cow, the time each hoof spends on the ground is no longer evenly distributed among the 4 hooves. The difference in the supporting phases increases with increasing severity of lameness. In the coordinate system used here, the points of the 4 supporting phases of a healthy cow are closely clustered (Figure 4a). For a lame cow, the minimum supporting phase is reduced, and the supporting phases become more separated in the plot; specifically, the supporting phase for the lame hoof will be reduced due to load reduction (Figure $4 \mathrm{~b}$ ). When there is severe lameness in a cow, the supporting phase will be significantly reduced (Figure 4c). Therefore, the features of the supporting phase of a lame cow can be used to detect lameness and identify the lame hoof or hooves.

\section{Classification Accuracy}

The speed thresholds in the lameness detection algorithm were selected manually based on an analysis of the data, and $t_{L s}$ and $t_{H s}$ were assigned values of $0.65 \mathrm{~s}$ and $0.9 \mathrm{~s}$, respectively. The lameness classification thresholds were calculated by sampling; for this purpose, 75 cows were randomly selected from among the 100 cows of all 3 lameness grades for algorithm threshold calculations. The results are shown in Table 1.

In Table $1, t_{1}$ and $t_{2}$ are the calculated classification thresholds. The difference between the maximum and minimum supporting phases was calculated for each cow, and these values were then classified based on the speed and locomotion scores. The corresponding range of supporting phase differences for each category was calculated, and the mean value of the 2 critical values for adjacent locomotion scores in the same speed class was taken as the corresponding classification threshold. The remaining 25 cows in the sample were used to verify the algorithm, and the results are shown in Tables 2 and 3.

In Table 2, the supporting phases and locomotion scores of these 25 cows are shown; the classification accuracy was $96 \%$. Table 3 presents the confusion matrix produced by calculating the number of samples classified in each class, which can be used to calculate the sensitivity and specificity by means of Equations 4 and 5 (Viazzi et al., 2013). As shown in Table 3, the sensitivity for scores of 1 and 2 were $100 \%$, and the sensitivity for a score of 3 was $83 \%$. The specificity for scores of 1 and 3 were $100 \%$, and the specificity for a score of 2 was $95 \%$. To evaluate the agreement between the observer scores and the algorithm results, the kappa coefficient was calculated and found to be 0.93 . The detection effect for distinguishing cows with no lameness from cows with severe lameness was apparent. Among the detection results for all cows, the algorithm misclassified only 1 cow with severe lameness as having only mild lameness (specifically, cow 22 in Table 2):

$$
\begin{gathered}
\text { sensitivity }_{c}=\frac{C M_{c, c}}{\sum_{j=1}^{k} C M_{c, j}}, \\
\text { specificity }_{c}=\frac{\sum_{i=1, i \neq c}^{k} \sum_{j=1, j \neq c}^{k} C M_{i, j}}{\sum_{i=1, i \neq c}^{k} \sum_{j=1}^{k} C M_{i, j}},
\end{gathered}
$$


where $C M_{i, j}$ is the value in the $i$ th row and $j$ th column of the confusion matrix, $k$ is the number of classes, and $c$ is a particular class.
In Table 4, the identified lame hooves of the cows, defined as those for which the difference between the supporting phase for the given hoof and the maximum

(a)

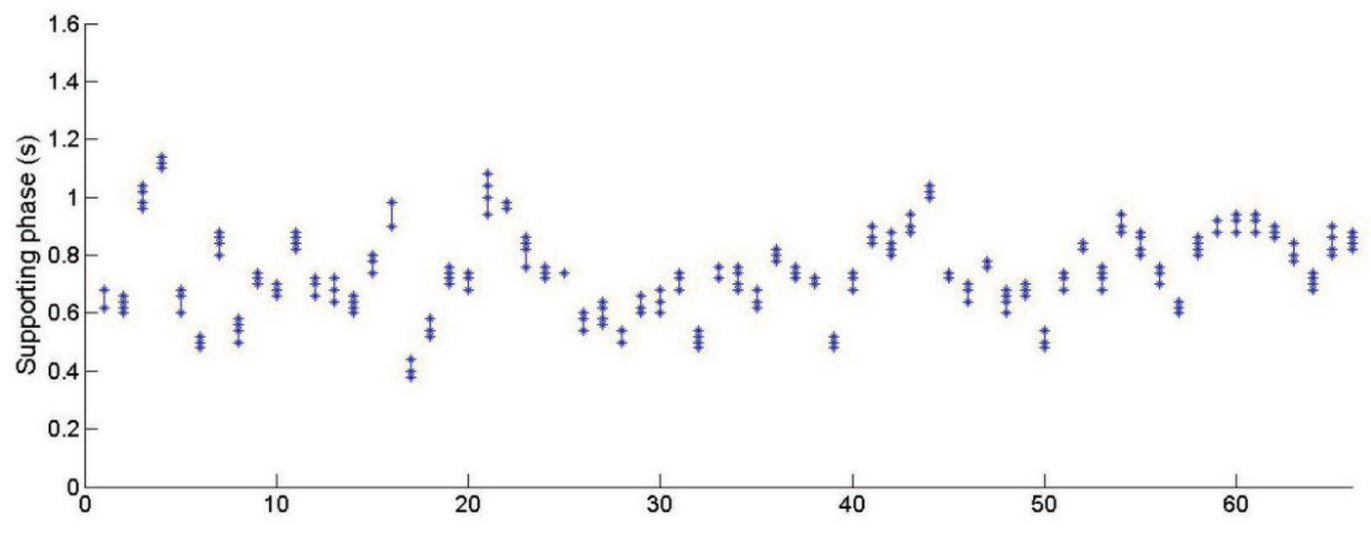

(b)

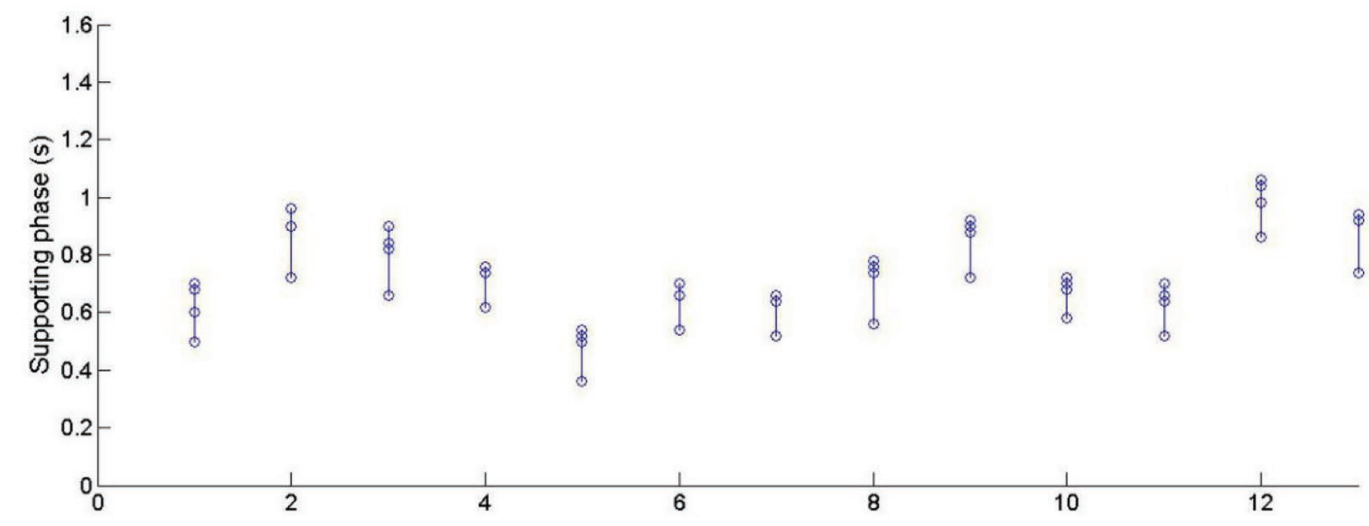

(c)

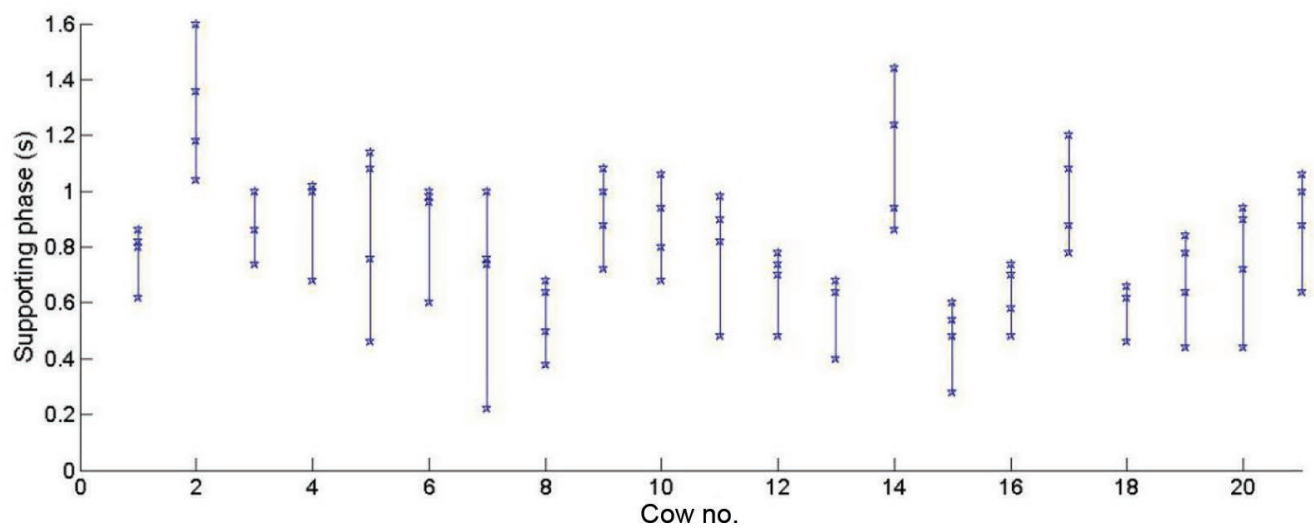

Figure 4. The supporting phases of cows with locomotion scores of (a) 1 (no lameness), (b) 2 (mild lameness), and (c) 3 (severe lameness). Each position on the horizontal axes represents an individual cow. 
Table 1. Threshold calculation results (in seconds) for the lameness classification algorithm based on the supporting phase ${ }^{1}$

\begin{tabular}{|c|c|c|c|c|c|}
\hline \multirow[b]{2}{*}{ Speed } & \multicolumn{3}{|c|}{ Range of $t_{m a x i}-t_{m i n i}$} & \multirow[b]{2}{*}{$t_{1}$} & \multirow[b]{2}{*}{$t_{2}$} \\
\hline & Score 1 & Score 2 & Score 3 & & \\
\hline Low & $0.04-0.08$ & $0.14-0.18$ & $0.20-0.28$ & 0.11 & 0.19 \\
\hline Medium & $0-0.10$ & $0.14-0.22$ & $0.24-0.32$ & 0.12 & 0.23 \\
\hline High & $0.02-0.14$ & $0.20-0.24$ & $0.26-0.78$ & 0.17 & 0.25 \\
\hline
\end{tabular}

${ }^{1}$ Scores: $1=$ no lameness; $2=$ mild lameness; $3=$ severe lameness; $t_{\max }$ $=$ the maximum supporting phase of the $i$ th cow; $t_{\text {mini }}=$ the minimum supporting phase of the $i$ th cow; $t_{1}$ and $t_{2}$ denote the lameness classification thresholds.

supporting phase was greater than the classification threshold, are compared with those identified via manual detection. The accuracy rate for lame hoof detection was $93 \%$. The sensitivity was $94 \%$, and the specificity was $100 \%$, as shown in Table 5 .

\section{Positioning Accuracy}

In this study, the RFB_NET_SSD deep learning network was used to detect the locations of cow legs (Figure 5). The general accuracy evaluation indicator for deep learning is the mean average precision (AP), which is the mean of all AP values for classification; when the mean AP is high, the detection effect of the algorithm is satisfactory (Jiang et al., 2019). The indicator used for detection speed evaluation is the average number of frames per second ( $\mathbf{a N F}$ ); the greater the $\mathrm{aNF}$ is, the faster the detection speed. Because only one category of object is detected here, the mean AP is equal to the AP. In this study, the mean AP for cow leg location detection is $87.0 \%$, and the detection frame rate in terms of the aNF is 83.3 frames/s.

\section{DISCUSSION}

To date, many studies on methods of detecting cow lameness based on computer vision have been published, thus providing a good research foundation. How-
Table 2. Results (in seconds) of the lameness classification algorithm based on the supporting phase

\begin{tabular}{|c|c|c|c|c|c|c|}
\hline \multirow{2}{*}{$\begin{array}{l}\text { Cow } \\
\text { no. }\end{array}$} & \multicolumn{4}{|c|}{ Supporting phase ${ }^{1}$} & \multirow{2}{*}{$\begin{array}{c}\text { Observer } \\
\text { score }^{2}\end{array}$} & \multirow[b]{2}{*}{ Result } \\
\hline & $\mathrm{LF}$ & $\mathrm{RF}$ & $\mathrm{LH}$ & $\mathrm{RH}$ & & \\
\hline 1 & 0.90 & 0.94 & 0.94 & 0.88 & 1 & 1 \\
\hline 2 & 0.68 & 0.72 & 0.74 & 0.70 & 1 & 1 \\
\hline 3 & 0.88 & 0.88 & 0.86 & 0.90 & 1 & 1 \\
\hline 4 & 0.92 & 0.88 & 0.88 & 0.88 & 1 & 1 \\
\hline 5 & 0.84 & 0.84 & 0.78 & 0.80 & 1 & 1 \\
\hline 6 & 0.82 & 0.84 & 0.82 & 0.84 & 1 & 1 \\
\hline 7 & 0.94 & 0.94 & 0.92 & 0.88 & 1 & 1 \\
\hline 8 & 0.68 & 0.72 & 0.76 & 0.74 & 1 & 1 \\
\hline 9 & 0.64 & 1.06 & 1.00 & 0.90 & 3 & 3 \\
\hline 10 & 0.70 & 0.68 & 0.58 & 0.72 & 2 & 2 \\
\hline 11 & 0.94 & 0.94 & 0.88 & 0.92 & 1 & 1 \\
\hline 12 & 0.58 & 0.48 & 0.70 & 0.74 & 3 & 3 \\
\hline 13 & 0.86 & 1.04 & 1.06 & 0.98 & 2 & 2 \\
\hline 14 & 0.92 & 0.94 & 0.74 & 0.94 & 2 & 2 \\
\hline 15 & 0.86 & 0.80 & 0.90 & 0.82 & 1 & 1 \\
\hline 16 & 0.90 & 0.72 & 0.94 & 0.44 & 3 & 3 \\
\hline 17 & 0.64 & 0.44 & 0.78 & 0.84 & 3 & 3 \\
\hline 18 & 0.82 & 0.84 & 0.88 & 0.86 & 1 & 1 \\
\hline 19 & 0.88 & 0.86 & 0.82 & 0.80 & 1 & 1 \\
\hline 20 & 0.50 & 0.48 & 0.50 & 0.54 & 1 & 1 \\
\hline 21 & 0.60 & 0.62 & 0.64 & 0.60 & 1 & 1 \\
\hline 22 & 0.62 & 0.46 & 0.66 & 0.66 & 3 & 2 \\
\hline 23 & 0.64 & 0.52 & 0.66 & 0.70 & 2 & 2 \\
\hline 24 & 1.08 & 1.2 & 0.78 & 0.88 & 3 & 3 \\
\hline 25 & 0.36 & 0.50 & 0.52 & 0.54 & 2 & 2 \\
\hline
\end{tabular}

${ }^{1} \mathrm{LF}=$ left fore hoof supporting phase; $\mathrm{RF}=$ right fore hoof supporting phase; $\mathrm{LH}=$ left hind hoof supporting phase; $\mathrm{RH}=$ right hind hoof supporting phase.

${ }^{2}$ Scores: $1=$ no lameness; $2=$ mild lameness; $3=$ severe lameness.

ever, some problems still need to be resolved. Cows are complex, individual, and time-varying systems (Berckmans, 2008). Lameness detection is often limited by the large differences among individual cows, which must be considered by automatic lameness detection systems (Viazzi et al., 2013). Some lameness detection methods extract the characteristics of a cow via comparisons among cows to determine whether a cow is lame, but this approach is affected by individual characteristics. By contrast, the supporting phase measurement method compares the characteristics of the 4 hooves of the same cow, thereby reducing the influence of individual

Table 3. Confusion matrix and classification evaluation of the supporting phase-based lameness classification algorithm $^{1}$

\begin{tabular}{|c|c|c|c|c|c|}
\hline \multirow[b]{2}{*}{ Classified by observers } & \multicolumn{3}{|c|}{ Classified by the algorithm (no.) } & \multirow[b]{2}{*}{ Total (no.) } & \multirow[b]{2}{*}{ Sensitivity (\%) } \\
\hline & Score 1 & Score 2 & Score 3 & & \\
\hline Score 1 & 14 & 0 & 0 & 14 & 100 \\
\hline Score 2 & 0 & 5 & 0 & 5 & 100 \\
\hline Score 3 & 0 & 1 & 5 & 6 & 83 \\
\hline Specificity (\%) & 100 & 95 & 100 & & \\
\hline
\end{tabular}

${ }^{1}$ Scores: $1=$ no lameness; $2=$ mild lameness; $3=$ severe lameness. 
Table 4. Results of lame hoof detection ${ }^{1}$

\begin{tabular}{lcll}
\hline Cow $^{2}$ & Observer score $^{3}$ & $H_{L}{ }^{4}$ & Manual detection \\
\hline 9 & 3 & $\mathrm{LF}$ & $\mathrm{LF}, \mathrm{RH}$ \\
10 & 2 & $\mathrm{LH}$ & $\mathrm{LH}$ \\
12 & 3 & $\mathrm{LF}, \mathrm{RF}$ & $\mathrm{LF}, \mathrm{RF}$ \\
13 & 2 & $\mathrm{LF}$ & $\mathrm{LF}$ \\
14 & 2 & $\mathrm{LH}$ & $\mathrm{LH}$ \\
16 & 3 & $\mathrm{RF}, \mathrm{RH}$ & $\mathrm{RF}, \mathrm{RH}$ \\
17 & 3 & $\mathrm{LF}, \mathrm{RF}$ & $\mathrm{LF}, \mathrm{RF}$ \\
22 & 3 & $\mathrm{RF}$ & $\mathrm{RF}$ \\
23 & 2 & $\mathrm{RF}$ & $\mathrm{RF}$ \\
24 & 3 & $\mathrm{LH}, \mathrm{RH}$ & $\mathrm{LH}, \mathrm{RH}$ \\
25 & 2 & $\mathrm{LF}$ & $\mathrm{LF}$ \\
\hline
\end{tabular}

$\overline{{ }^{1} \mathrm{LF}}=$ left fore hoof supporting phase; $\mathrm{RF}=$ right fore hoof supporting phase; $\mathrm{LH}=$ left hind hoof supporting phase; $\mathrm{RH}=$ right hind hoof supporting phase.

${ }^{2}$ Cow number corresponds to that in Table 2 .

${ }^{3}$ Scores: $1=$ no lameness; $2=$ mild lameness; $3=$ severe lameness.

${ }^{4}$ Lame hooves from automatic detection.

characteristics. For example, although the hand sizes of different individuals may differ, the sizes of both hands on a single healthy person should be approximately the same.

A lame cow is unwilling to bear weight on the affected leg or legs (Thomsen et al., 2008). Computer vision technology cannot directly detect the degree of weight bearing, but because a lame cow will reduce the load on a hoof by shortening the time for which the hoof is in contact with the ground, computer vision technology can detect the supporting phase and use this information as a proxy for the load-bearing degree.

The supporting phases and locomotion scores of several cows are listed in Table 6. A statistical analysis of the supporting phases of the cows shows that there is a positive correlation between the difference in the supporting phases and the locomotion score. The corresponding Spearman rank correlation coefficient is 0.864 . The supporting phases of the 4 hooves of a healthy cow are basically the same, as shown by the cows numbered 1 to 5 in Table 6 and the cows represented in Figure $4 \mathrm{a}$. By contrast, the supporting phases of the 4 hooves of a mildly lame cow are different, although in some cases these differences are not obvious, with lameness generally limited to one hoof, as shown by the cows numbered 6 to 10 in Table 6 and the cows represented

Table 5. Confusion matrix for lame hoof detection (no.)

\begin{tabular}{lcc}
\hline & \multicolumn{2}{c}{$H_{L}{ }^{1}$} \\
\cline { 2 - 3 } Manual detection & Lame hoof & Healthy hoof \\
\hline Lame hoof & 15 & 1 \\
Healthy hoof & 0 & 28 \\
\hline
\end{tabular}

${ }^{1}$ Lame hooves from automatic detection.
Table 6. Supporting phases (in seconds) and locomotion scores of 15 cows with different degrees of lameness

\begin{tabular}{lccccc}
\hline & \multicolumn{5}{c}{ Supporting phase $^{1}$} \\
Cow \\
\cline { 2 - 4 } no. & LF & RF & LH & RH & $\begin{array}{c}\text { Observer } \\
\text { score }^{2}\end{array}$ \\
\hline 1 & 0.62 & 0.68 & 0.68 & 0.62 & 1 \\
2 & 0.66 & 0.60 & 0.62 & 0.64 & 1 \\
3 & 1.02 & 0.96 & 0.98 & 1.04 & 1 \\
4 & 1.12 & 1.14 & 1.10 & 1.14 & 1 \\
5 & 0.52 & 0.50 & 0.48 & 0.50 & 1 \\
6 & 0.70 & 0.60 & 0.68 & 0.50 & 2 \\
7 & 0.90 & 0.90 & 0.96 & 0.72 & 2 \\
8 & 0.70 & 0.54 & 0.66 & 0.70 & 2 \\
9 & 0.62 & 0.76 & 0.74 & 0.76 & 2 \\
10 & 0.36 & 0.50 & 0.52 & 0.54 & 2 \\
11 & 1.18 & 1.60 & 1.36 & 1.04 & 3 \\
12 & 0.46 & 0.76 & 1.08 & 1.14 & 3 \\
13 & 0.74 & 1.00 & 0.22 & 0.76 & 3 \\
14 & 1.00 & 0.60 & 0.96 & 0.98 & 3 \\
15 & 0.72 & 1.08 & 0.88 & 1.00 & 3 \\
\hline
\end{tabular}

${ }^{1} \mathrm{LF}=$ left fore hoof supporting phase; $\mathrm{RF}=$ right fore hoof supporting phase; $\mathrm{LH}=$ left hind hoof supporting phase; $\mathrm{RH}=$ right hind hoof supporting phase.

${ }^{2}$ Scores: $1=$ no lameness; $2=$ mild lameness; $3=$ severe lameness.

in Figure 4b. The supporting phases of a severely lame cow are obviously different, with the supporting phases of severely lame hooves being shorter than normal phases and potentially indicating lameness in multiple hooves, as shown by the cows numbered 11 to 15 in Table 6 and the cows represented in Figure 4c.

In this paper, we have analyzed the correlation between the maximum difference in the supporting phases and the locomotion score for these 100 cows, as shown in Figure 6. From the data analysis, it is evident that the walking speed of dairy cows has an effect on this correlation. When the difference between the supporting phases of fast-walking cows and slow-walking cows is small, the lameness of the fast-walking cows is serious.

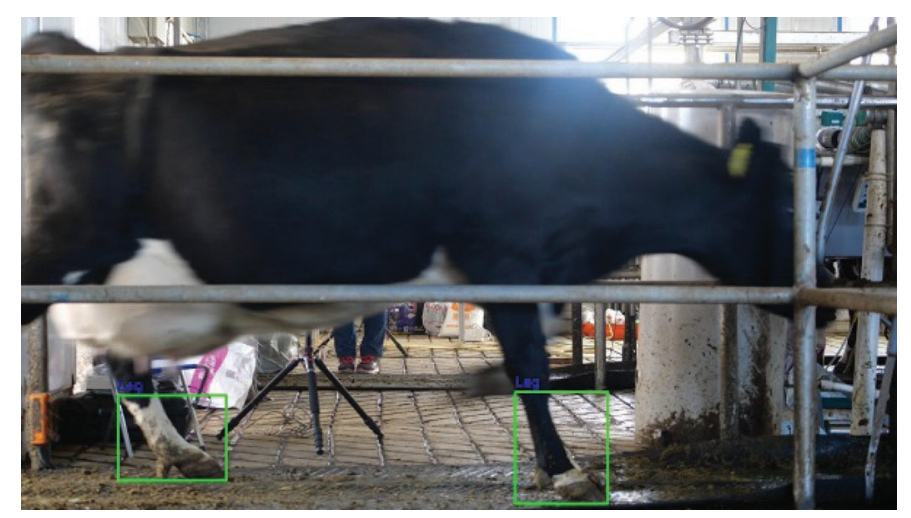

Figure 5. Detection results for cow leg locations. 


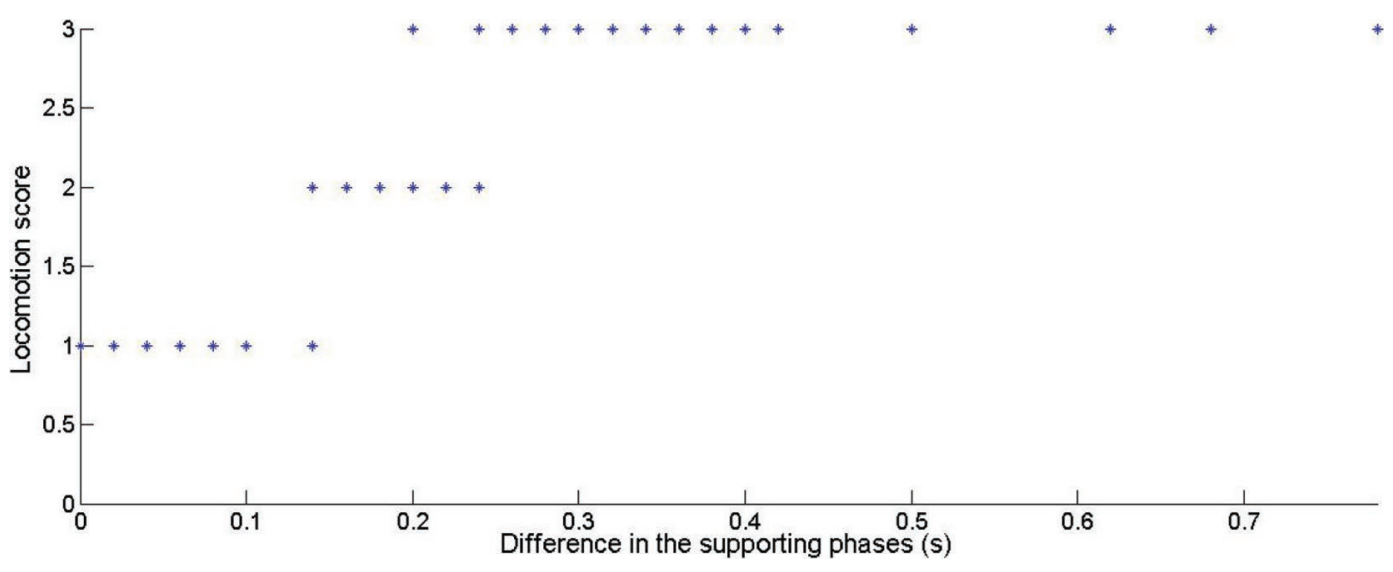

Figure 6. The differences in the supporting phases for each locomotion score. Due to the influence of the movement speed, there is some overlap among the supporting phase differences for the 3 locomotion scores. $1=$ no lameness; $2=$ mild lameness; and $3=$ severe lameness.

Therefore, the speed of the cow has been considered in the construction of the lameness detection algorithm.

The accuracy of the algorithm proposed in this paper for cow lameness detection based on the supporting phase has been shown to be $96 \%$. According to the official specifications of StepMetrix (Kruegers Bou-Matic, Clintonville, WI), the accuracy of that system is $85 \%$ (Viazzi et al., 2013). In recent years, the accuracy of various methods (e.g., trackway overlap, back arch, head position, leg swing) based on computer vision has reached approximately 95\% (Song et al., 2008; Poursaberi et al., 2010). Therefore, the lameness detection algorithm proposed in this paper provides better detection accuracy than these methods due to the high resolution of the detection strategy based on the analysis of the supporting phase. In addition, the proposed algorithm has a good detection effect for mild and moderate lameness. Moreover, it enables the visual detection of lame hooves.

It is necessary to identify which hoof is affected by lameness (Viazzi et al., 2013; Van De Gucht et al., 2017) for targeted treatment. According to the data in Table 2, it is easy to determine whether a cow is lame and which hoof is lame by analyzing the differences in the supporting phase of each hoof. Notably, a lame cow will reduce the load-bearing time of a lame hoof when walking. Unlike back arch, head bob, and other characteristics, the supporting phase is related only to the characteristics of each cow's hooves, which makes it easy to assess each hoof individually. In this paper, the accuracy of the detection method for identifying a lame hoof by assessing the difference in characteristics between a lame hoof and a normal hoof was $93 \%$. However, the algorithm defines the hoof with the longest supporting phase as the normal hoof; therefore, if there is lameness in all 4 hooves of a cow, this method cannot detect the hoof with the mildest lameness because the hoof with the mildest lameness is assumed to be a normal hoof.

Deep learning technology can reduce the effects of the environment and cow movement (Jiang et al., 2019) when applied for target recognition and extraction and cow lameness detection based on computer vision. Facebook used the PASCAL VOC data set to test the RFB_NET_SSD deep learning network in the Python deep learning framework, and the mean AP and aNF were $80.5 \%$ and 83.0 frames/s, respectively. In the present study, deep learning was used for highprecision cow leg position detection with good results; the positioning accuracy in terms of the mean $\mathrm{AP}$ was $87.0 \%$, and the detection frame rate in terms of the aNF was 83.3 frames/s. The results verify that the detection method used in this paper can effectively and quickly locate cow legs in images. The supporting phase-based detection method proposed in this paper can thus be successfully applied using computer vision technology for lameness detection. However, there were a few false detections and missed detections with this approach. Accordingly, these detection errors were analyzed. In some cases in which farm workers appeared in an image, a human leg was detected as a cow leg because the large boots that workers wear are similar to cow hooves from certain camera perspectives. Additionally, some shadow phenomena may occur when a cow leg is rapidly swinging, which can affect the detection accuracy. In future research, the following measures can be taken to improve the accuracy. First, the appearance of workers in the video should be avoided. Second, the cow leg positions can be related to the overall position of the cow, instead of using only the shape for detection, to 
avoid the occurrence of false detections. Finally, a highspeed camera with better performance could be used to more accurately capture moving objects, eliminate shadow phenomena, and reduce missed detections.

In future research on cow lameness detection, we hope to combine the proposed supporting phase-based method with other methods (e.g., methods based on back arch, head bob, speed, and tracking) to perform multifeature detection integrated with a computer vision system. The combination of multiple methods can improve the robustness and accuracy of detection because it is difficult to detect all lame cows accurately based on only a single feature (Schlageter-Tello et al., 2015; Jones, 2017). A spatiotemporal dual-flow convolutional neural network could also be considered as a deep learning model to analyze the temporal and spatial characteristics of cow walking behavior to directly detect lameness. The technology proposed in this study based on computer vision has broad application prospects in the real-time, accurate detection of lameness in dairy cattle, which can be expected to further improve the welfare of cows and get rid of the negative effect of lameness on the dairy industry.

\section{CONCLUSIONS}

In this study, we proposed a new and individualized detection strategy based on an analysis of the supporting phase to detect lameness in cows and identify lame hooves by processing video using deep learning. The correlation between the supporting phase and the lameness of a cow was investigated and found to be high. The results show that the proposed detection strategy effectively eliminates the effects of the characteristics of individual cows and achieves improved classification accuracy; thus, analyses of the supporting phase based on computer vision can be successfully performed to detect lameness. Additionally, according to the results for the correlation between the supporting phase and the degree of lameness, the supporting phase should be considered a key factor for addressing the shortcomings of existing methods. This information can be further integrated into computer vision-based automatic detection systems, which is anticipated to be a very important part of our future work.

\section{ACKNOWLEDGMENTS}

This work was supported by the National Key R\&D Program of China (no. 2018YFD050070502), Beijing. The authors have no conflicts of interest to declare.

\section{REFERENCES}

Adair, S., M. Baus, R. Bell, M. Boero, C. Bussy, F. Cardenas, T. Casey, J. Castro, W. Davis, M. Erskine, R. Farr, A. Fischer, B. Forbes, T. Ford, R. Genovese, R. Gottschalk, M. Hoge, C. Honnas, G. Hunter, J. Joyce, A. Kaneps, K. Keegan, J. Kramer, R. Labens, C. Lischer, J. Marshall, M. Oosterlinck, P. Radue, R. Redding, S. Reed, M. Rick, E. Santschi, M. Schoonover, M. Schramme, J. Schumacher, R. Stephenson, R. Thaler, J. V. Nielsen, and D. Wilson. 2019. Letter to the editor: A response to 'What is lameness and what (or who) is the gold standard to detect it?' Equine Vet. J. 51:270-272. https://doi.org/10.1111/evj.13043.

Adams, A. E., J. E. Lombard, C. P. Fossler, I. N. Roman-Muniz, and C. A. Kopral. 2017. Associations between housing and management practices and the prevalence of lameness, hock lesions, and thin cows on US dairy operations. J. Dairy Sci. 100:2119-2136. https://doi.org/10.3168/jds.2016-11517.

Alsaaod, M., M. Fadul, and A. Steiner. 2019. Automatic lameness detection in cattle. Vet. J. 246:35-44. https://doi.org/10.1016/j .tvjl.2019.01.005.

Alsaaod, M., C. Syring, J. Dietrich, M. G. Doherr, T. Gujan, and A. Steiner. 2014. A field trial of infrared thermography as a noninvasive diagnostic tool for early detection of digital dermatitis in dairy cows. Vet. J. 199:281-285. https://doi.org/10.1016/j.tvjl .2013.11.028.

Berckmans, D. 2008. Precision livestock farming (PLF). Comput. Electron. Agric. 62:1. https://doi.org/10.1016/j.compag.2007.09.002.

Booth, C. J., L. D. Warnick, Y. T. Grohn, D. O. Maizon, C. L. Guard, and D. Janssen. 2004. Effect of lameness on culling in dairy cows. J. Dairy Sci. 87:4115-4122. https://doi.org/10.3168/jds.S0022 -0302(04)73554-7.

de Mol, R. M., G. Andre, E. J. Bleumer, J. T. Van Der Werf, Y. De Haas, and C. G. Van Reenen. 2013. Applicability of day-to-day variation in behavior for the automated detection of lameness in dairy cows. J. Dairy Sci. 96:3703-3712. https://doi.org/10.3168/ jds.2012-6305.

Engel, B., G. Bruin, G. Andre, and W. Buist. 2003. Assessment of observer performance in a subjective scoring system: Visual classification of the gait of cows. J. Agric. Sci. 140:317-333. https:// doi.org/10.1017/S0021859603002983.

Flower, F. C., D. J. Sanderson, and D. M. Weary. 2006. Effects of milking on dairy cow gait. J. Dairy Sci. 89:2084-2089. https://doi .org/10.3168/jds.S0022-0302(06)72278-0.

Flower, F. C., and D. M. Weary. 2009. Gait assessment in dairy cattle. Animal 3:87-95. https://doi.org/10.1017/S1751731108003194.

Green, L. E., V. J. Hedges, Y. H. Schukken, R. W. Blowey, and A. J. Packington. 2002. The impact of clinical lameness on the milk yield of dairy cows. J. Dairy Sci. 85:2250-2256. https://doi.org/10 .3168/jds.S0022-0302(02)74304-X.

Grimm, K., B. Haidn, M. Erhard, M. Tremblay, and D. Dopfer. 2019. New insights into the association between lameness, behavior, and performance in Simmental cows. J. Dairy Sci. 102:2453-2468. https://doi.org/10.3168/jds.2018-15035.

Hoffman, A. C., D. A. Moore, J. Vanegas, and J. R. Wenz. 2014. Association of abnormal hind-limb postures and back arch with gait abnormality in dairy cattle. J. Dairy Sci. 97:2178-2185. https:// doi.org/10.3168/jds.2013-7528.

Jiang, B., Q. Wu, X. Yin, D. Wu, H. Song, and D. He. 2019. FLYOLOv3 deep learning for key parts of dairy cow body detection. Comput. Electron. Agric. 166:104982. https://doi.org/10.1016/j .compag.2019.104982.

Jones, B. W. 2017. Behavioral gait change characterization and detection using precision dairy monitoring technologies. $\mathrm{PhD}$ Thesis. Agriculture, Food and Environment, Kentucky Univ., Lexington.

Kang, X., X. D. Zhang, and G. Liu. 2019. Hoof location method of lame dairy cows based on machine vision. Nongye Jixie Xuebao 50:276-282.

Leach, K. A., E. S. Paul, H. R. Whay, Z. E. Barker, C. M. Maggs, A. K. Sedgwick, and D. C. Main. 2013. Reducing lameness in 
dairy herds - Overcoming some barriers. Res. Vet. Sci. 94:820-825. https://doi.org/10.1016/j.rvsc.2012.10.005.

Liang, D., L. M. Arnold, C. J. Stowe, R. J. Harmon, and J. M. Bewley. 2017. Estimating US dairy clinical disease costs with a stochastic simulation model. J. Dairy Sci. 100:1472-1486. https://doi.org/10 $.3168 /$ jds. 2016-11565.

Liu, J., R. M. Dyer, N. K. Neerchal, U. Tasch, and P. G. Rajkondawar. 2011. Diversity in the magnitude of hind limb unloading occurs with similar forms of lameness in dairy cows. J. Dairy Res. 78:168177. https://doi.org/10.1017/S0022029911000057.

Liu, S., D. Huang, and Y. Wang. 2018. Receptive field block net for accurate and fast object detection. Pages 404-419 in Proc. Comput. Vis. ECCV 2018. Springer International Publishing, Cham, Switzerland.

Maertens, W., J. Vangeyte, J. Baert, A. Jantuan, K. C. Mertens, S. De Campeneere, A. Pluk, G. Opsomer, S. Van Weyenberg, and A. Van Nuffel. 2011. Development of a real time cow gait tracking and analysing tool to assess lameness using a pressure sensitive walkway: The GAITWISE system. Biosyst. Eng. 110:29-39. https: //doi.org/10.1016/j.biosystemseng.2011.06.003.

Main, D. C., Z. E. Barker, K. A. Leach, N. J. Bell, H. R. Whay, and W. J. Browne. 2010. Sampling strategies for monitoring lameness in dairy cattle. J. Dairy Sci. 93:1970-1978. https://doi.org/10 $.3168 /$ jds.2009-2500.

Mandel, R., H. Harazy, L. Gygax, C. J. Nicol, A. Ben-David, H. R. Whay, and E. Klement. 2018. Short communication: Detection of lameness in dairy cows using a grooming device. J. Dairy Sci. 101:1511-1517. https://doi.org/10.3168/jds.2017-13207.

Murray, R. D., D. Y. Downham, M. J. Clarkson, W. B. Faull, J. W. Hughes, F. J. Manson, J. B. Merritt, W. B. Russell, J. E. Sutherst, and W. R. Ward. 1996. Epidemiology of lameness in dairy cattle: Description and analysis of foot lesions. Vet. Rec. 138:586-591. https://doi.org/10.1136/vr.138.24.586.

O'Callaghan, K. A., P. Cripps, D. Y. Downham, and R. Murray. 2003. Subjective and objective assessment of pain and discomfort due to lameness in dairy cattle. Anim. Welf. 12:605-610.

Pastell, M., L. Hanninen, A. M. de Passille, and J. Rushen. 2010. Measures of weight distribution of dairy cows to detect lameness and the presence of hoof lesions. J. Dairy Sci. 93:954-960. https://doi .org/10.3168/jds.2009-2385.

Pastell, M., M. Hautala, V. Poikalainen, J. Praks, I. Veermäe, M. Kujala, and J. Ahokas. 2008a. Automatic observation of cow leg health using load sensors. Comput. Electron. Agric. 62:48-53. https://doi.org/10.1016/j.compag.2007.09.003.

Pastell, M., M. Kujala, A. M. Aisla, M. Hautala, V. Poikalainen, J. Praks, I. Veermäe, and J. Ahokas. 2008b. Detecting cow's lameness using force sensors. Comput. Electron. Agric. 64:34-38. https: //doi.org/10.1016/j.compag.2008.05.007.

Pastell, M. E., and M. Kujala. 2007. A probabilistic neural network model for lameness detection. J. Dairy Sci. 90:2283-2292. https:// doi.org/10.3168/jds.2006-267.

Pluk, A., C. Bahr, T. Leroy, A. Poursaberi, X. Song, E. Vranken, W. Maertens, A. Van Nuffel, and D. Berckmans. 2010. Evaluation of step overlap as an automatic measure in dairy cow locomotion. Trans. ASABE 53:1305-1312. https://doi.org/10.13031/2013 32580 .

Pluk, A., C. Bahr, A. Poursaberi, W. Maertens, A. Van Nuffel, and D. Berckmans. 2012. Automatic measurement of touch and release angles of the fetlock joint for lameness detection in dairy cattle using vision techniques. J. Dairy Sci. 95:1738-1748. https://doi.org/ $10.3168 /$ jds.2011-4547.

Poikalainen, V., J. Praks, E. Kokin, A. Aland, I. Veermäe, S. Peets, J. Ahokas, M. Pastell, M. Hautala, D. Berckmans, C. Bahr, and D. Miljkovic. 2010. Elaboration of basic methods for automatic analysis of cows' gait. Agron. Res. (Tartu) 8:216-225.

Poursaberi, A., C. Bahr, A. Pluk, A. Van Nuffel, and D. Berckmans. 2010. Real-time automatic lameness detection based on back posture extraction in dairy cattle: Shape analysis of cow with image processing techniques. Comput. Electron. Agric. 74:110-119. https://doi.org/10.1016/j.compag.2010.07.004.
Rajkondawar, P. G., M. Liu, R. M. Dyer, N. K. Neerchal, U. Tasch, A. M. Lefcourt, B. Erez, and M. A. Varner. 2006. Comparison of models to identify lame cows based on gait and lesion scores, and limb movement variables. J. Dairy Sci. 89:4267-4275. https://doi .org/10.3168/jds.S0022-0302(06)72473-0.

Rees, G. 2014. Fate of a severely lame cow. In Pract. 36:526-527. https: //doi.org/10.1136/inp.g6399.

Schlageter-Tello, A., E. A. M. Bokkers, P. W. G. G. Koerkamp, T. Van Hertem, S. Viazzi, C. E. B. Romanini, I. Halachmi, C. Bahr, D. Berckmans, and K. Lokhorst. 2015. Relation between observed locomotion traits and locomotion score in dairy cows. J. Dairy Sci. 98:8623-8633. https://doi.org/10.3168/jds.2014-9059.

Scott, G. B. 1989. Changes in limb loading with lameness for a number of Friesian cattle. Br. Vet. J. 145:28-38. https://doi.org/10.1016/ 0007-1935(89)90005-5.

Sjöström, K., N. Fall, I. Blanco-Penedo, J. E. Duval, M. Krieger, and U. Emanuelson. 2018. Lameness prevalence and risk factors in organic dairy herds in four European countries. Livest. Sci. 208:4450. https://doi.org/10.1016/j.livsci.2017.12.009.

Song, H., B. Jiang, Q. Wu, T. Li, and D. He. 2018. Detection of dairy cow lameness based on fitting line slope feature of head and neck outline. Nongye Gongcheng Xuebao (Beijing) 34:190-199.

Song, X., T. Leroy, E. Vranken, W. Maertens, B. Sonck, and D. Berckmans. 2007. Automatic detection of lameness in dairy cattle (1)Gait analysis in dairy cattle by vision. Commun. Agric. Appl. Biol. Sci. 72:23-27. https://doi.org/10.1016/j.compag.2008.05.016.

Song, X., T. Leroy, E. Vranken, W. Maertens, B. Sonck, and D. Berckmans. 2008. Automatic detection of lameness in dairy cattleVision-based trackway analysis in cow's locomotion. Comput. Electron. Agric. 64:39-44. https://doi.org/10.1016/j.compag.2008 .05 .016 .

Sprecher, D. J., D. E. Hostetler, and J. B. Kaneene. 1997. A lameness scoring system that uses posture and gait to predict dairy cattle reproductive performance. Theriogenology 47:1179-1187. https:// doi.org/10.1016/S0093-691X(97)00098-8.

Thomsen, P. T., L. Munksgaard, and F. A. Togersen. 2008. Evaluation of a lameness scoring system for dairy cows. J. Dairy Sci. 91:119-126. https://doi.org/10.3168/jds.2007-0496.

Thorup, V. M., L. Munksgaard, P. E. Robert, H. W. Erhard, P. T. Thomsen, and N. C. Friggens. 2015. Lameness detection via legmounted accelerometers on dairy cows on four commercial farms. Animal 9:1704-1712. https://doi.org/10.1017/S1751731115000890.

Van De Gucht, T., S. Van Weyenberg, A. Van Nuffel, L. Lauwers, J. Vangeyte, and W. Saeys. 2017. Supporting the development and adoption of automatic lameness detection systems in dairy cattle: Effect of system cost and performance on potential market shares. Animals (Basel) 7:77. https://doi.org/10.3390/ani7100077.

Van Hertem, T., C. Bahr, A. Schlageter Tello, S. Viazzi, M. Steensels, C. E. Romanini, C. Lokhorst, E. Maltz, I. Halachmi, and D. Berckmans. 2016. Lameness detection in dairy cattle: Single predictor v. multivariate analysis of image-based posture processing and behaviour and performance sensing. Animal 10:1525-1532. https:// doi.org/10.1017/S1751731115001457.

Van Hertem, T., E. Maltz, A. Antler, C. E. Romanini, S. Viazzi, C. Bahr, A. Schlageter-Tello, C. Lokhorst, D. Berckmans, and I. Halachmi. 2013. Lameness detection based on multivariate continuous sensing of milk yield, rumination, and neck activity. J. Dairy Sci. 96:4286-4298. https://doi.org/10.3168/jds.2012-6188.

Van Nuffel, A., J. Vangeyte, K. C. Mertens, L. Pluym, S. De Campeneere, W. Saeys, G. Opsomer, and S. Van Weyenberg. 2013. Exploration of measurement variation of gait variables for early lameness detection in cattle using the GAITWISE. Livest. Sci. 156:88-95. https://doi.org/10.1016/j.livsci.2013.06.013.

Van Nuffel, A., I. Zwertvaegher, S. Van Weyenberg, M. Pastell, V. M. Thorup, C. Bahr, B. Sonck, and W. Saeys. 2015. Lameness detection in dairy cows: Part 2. Use of sensors to automatically register changes in locomotion or behavior. Animals (Basel) 5:861-885. https://doi.org/10.3390/ani5030388.

Viazzi, S., C. Bahr, A. Schlageter-Tello, T. Van Hertem, C. E. Romanini, A. Pluk, I. Halachmi, C. Lokhorst, and D. Berckmans. 2013. 
Analysis of individual classification of lameness using automatic measurement of back posture in dairy cattle. J. Dairy Sci. 96:257266. https://doi.org/10.3168/jds.2012-5806.

Viazzi, S., C. Bahr, T. Van Hertem, A. Schlageter-Tello, C. E. B. Romanini, I. Halachmi, C. Lokhorst, and D. Berckmans. 2014. Comparison of a three-dimensional and two-dimensional camera system for automated measurement of back posture in dairy cows. Comput. Electron. Agric. 100:139-147. https://doi.org/10.1016/j .compag.2013.11.005.

Walker, S. L., R. Smith, J. Routly, D. Jones, M. Morris, and H. Dobson. 2008. Lameness, activity time-budgets, and estrus expression in dairy cattle. J. Dairy Sci. 91:4552-4559. https://doi.org/10 $.3168 /$ jds.2008-1048.

Winckler, C., and S. Willen. 2001. The reliability and repeatability of a lameness scoring system for use as an indicator of welfare in dairy cattle. Acta Agric. Scand. A Anim. Sci. 51(Sup030):103-107. https://doi.org/10.1080/090647001316923162.
Zhao, K., J. M. Bewley, D. He, and X. Jin. 2018. Automatic lameness detection in dairy cattle based on leg swing analysis with an image processing technique. Comput. Electron. Agric. 148:226-236. https://doi.org/10.1016/j.compag.2018.03.014.

Zillner, J. C., N. Tücking, S. Plattes, T. Heggemann, and W. Büscher. 2018. Using walking speed for lameness detection in lactating dairy cows. Livest. Sci. 218:119-123. https://doi.org/10.1016/j.livsci .2018.10.005.

\section{ORCIDS}

X. Kang (ํ) https://orcid.org/0000-0001-9085-5253

X. D. Zhang @ https://orcid.org/0000-0003-3598-257X

G. Liu ( https://orcid.org/0000-0002-1004-1653 